\title{
S11. Psychopathological concepts of schizophrenia
}

THE SYMPTOMS OF SCHIZOPHRENIA: A CONCEPTUAL HISTORY G.E. Berrios

Department of Psychiatry, University of Cambridge, Addenbrooke's Hospital (Box 189), Cambridge, UK CBS 2 QQ

Conceptual confusion is one of the important obstacles to progress in neurobiological research in schizophrenia. Some of it is man-made and stems trom blindly following the fads of 'normal science'. There is little doubt, however, that there is also opaqueness in the subject matter itself. In either case, the use of analytical and historical techniques can help differentiate between obscurities pertaining to the language of description (i.e. symptommapping) and those inherent in the object itself. This paper offers an account of the way in which delusion, hallucination, though disorder, motility disorders, and other symptoms of schizophrenia were historically constructed. It then proceeds to reanalyze their status in the light of current meta-analytic categories such as symptom recognition, specificity, level of organization, hierarchy, completeness, susceptibility to quantification, etc. It shows that such approach distinguishes between the history of terms (etymology), concepts (conceptual history), and behaviours (behavioural palæntology); and that the conceptual history of symptoms is independent from the traditional linear Morel-to-Schneider history of the disease. It is concluded, inter alia, that the latter view, together with the fads of current research, have contributed to perpetuating a model of schizophrenia which has now reached the limits of its heuristic power.
CONCEPTS FRANCAIS CONCERNANT LA SCHIZOPHRENIE G.DABCOURI

Clinique de Psychiatrie de rUniversité de Nice, Hôpital Pasteur, B.P.69, 06002 Nice Cedex 1

Si on compare les criteres de classification français concernant la schizophrênie à ceux du D.S.M.III R, on constate : ecoles.

1. Ils sont moins précis et comportent quelques variations selon les

2. Le syndrome fondamental est en accord avec celui du D.S.M.III R, avec toutefois une priorité donnée aux signes négatifs : incohérence, impénétrabilité, discondance, indifférence affective.

3. Pour les formes cliniques, la correspondance avec celles du D.S.M. III R est la suivante:

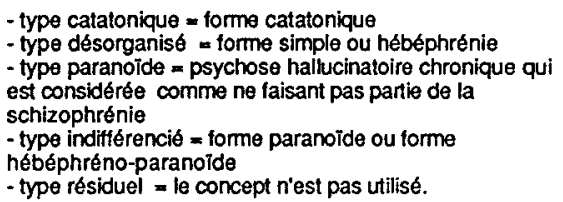

4. Quant aux troubles d'allure schizophrénique mais de courte durée. la psychiatrie française ne les a jamais inclus dans la schizophrénie mais les dénommait : bouffées délirantes ou psychoses délirantes aiguěs. 


\section{PSYCHOPATHOLOGICAL CONCEPTS OF SCHIZOPHRENIA}

\section{Ch. Mundt,}

Psychiatric University Hospital Heidelberg

Voss-Str. 4, D-69115 Heidelberg/Germany

Modern technology of investigation as for example neuroimaging or registration of sacchadic eye tracking has brought about such fascinating new results that conceptual considerations of the anthropological nature of schizophrenia seem of minor interest at present. However, interpretation of these findings remains too narrow if the anthropological frame of their underlying dysfunctions is disregarded.

The historically oldest concept was Bleuler's theory of schisms and disruption in personality structure and mental functions. Structural theories of schizophrenia have been adopted since by linguists who research on schizophrenic speech- and thought disturbances, also by psychoanalysts, in particular the structural and linguistic branch.

A somehow opposite view is taken by dynamistic concepts which can be traced back to the middle of the 19th century with the "secondary states of frailty". Dynamistic theories are alive in the positivenegative dichotomy and in Janzarik's structural-dynamic concept of the endogenous psychoses.

The most fundamental anthropological formulation of schizophrenia has been worked out by German phenomenologists who rely on Husserl. They claim a lack of constituting intersubjectivity as basic disturbance in schizophrenia.

Most recently, the work with associative networks by priming experiments with schizophrenics revives dynamic theories of overstimulation and disinhibition of the networks in thought disordered schizophrenics. For the explanation of modulations of the network activity old gestalt-psychology-terms and models as figurebackground-relationship are used again.

A remarkable convergence and integration of concepts can be observed. This development will be discussed.

THE BLEULERIAN CONCEPT OF SCHIZOPHAENIA TODAY

E. Gabriel

Psychiatric Hospital, Baumgartner Hōhe 1, A-1140 Vienna, Austria

The paper deals with an analysis of the concept of the group of schizophrenias of Eugen Bleuler and follows the further development of that concept in the Zurich school as the influence of that concept on intemational classification as well. It refers to the Bleulerian distinction between basic (or fundamental) and accessory symptoms and primary and secondary symptorns and depicts the impact of these concepts in present psychopathology, classification and clinical research and stresses the fruitfulness of referring to primary symptoms in the interpretation of empirical research data as it has been shown in several studies which have been executed in Vienna during the last 25 years.

\section{SCANDINAVIAN CONCEPTS OF SCHIZOPHRENIA Nils Retterst $\mid$}

Gaustad Hospital, Boks 24, Gaustad, N-0320 Oslo 3

Scandinavian concepts of schizophrenia differ, as they do in other countries. However, the Scandinavian concepts have been relatively strict. The Scandinavian psychiatrists have been inclined to use the diagnosis reactive psychoses where doubt has existed as to whether a diagnosis of schizophrenia should be given. Langfeldt (1939) introduced the term schizophreniform psychoses for these doubtful forms. Newer research (Hansen et al. 1992, Dahl et al. 1992) has demonstrated that the Scandinavian concepts for schizophrenia is in good accordance with the concept in DSM-III-R and also that reactive psychosis in Scandinavian multicenter reliability studies can be diagnosed as reliably as schizophrenia and affective psychosis. 